\title{
Saúde nas fronteiras: análise quantitativa e qualitativa da clientela do Centro Materno Infantil de Foz do Iguaçu, Brasil
}

\author{
Health at the border: quantitative and qualitative analysis \\ of patients treated at the Maternal and Child Care Center \\ in Foz do Iguaçu, Brazil
}

Fabio de Mello ${ }^{1}$

Cesar Gomes Victora ${ }^{2}$

Helen Gonçalves ${ }^{2}$

${ }^{1}$ Secretaria Municipal de Saúde, Prefeitura Municipal de Foz do Iguaçu. Av. Brasil 1637, Centro. 85851-000 Foz do Iguaçu PR Brasil. fabioenf@hotmail.com ${ }^{2}$ Programa de Pós-

Graduação em Epidemiologia Universidade Federal de Pelotas.
Abstract Foz do Iguaçu participates in the SIS-Fronteiras program and installed the Maternal and Child Care Center (CMI) to offer prenatal care service to pregnant Brazilian women resident in Paraguay (Brasiguaias). To analyze the characteristics of the CMI and compare the profile of Brasiguaias with pregnant Brazilian women resident in Brazil, a quantitative and qualitative approach in methodology was applied. It was found that Brasiguaias go to the CMI because of the precariousness of services of the Paraguayan Health System. They tend to be younger, bear more children, have lower education and are unmarried compared with pregnant Brazilian woman resident in Brazil. They omit where they live to avoid being denied the right or receiving inferior treatment than local pregnant Brazilian women and seek obstetric treatment later to avoid being denied attendance. Pregnant Brazilian women resident in Paraguay are onerous to the municipality, especially due to misinformation about their reproductive and pregnancy history, which increases the chances of undergoing cesarean delivery and hospitalization of the mother and/or infant due to complications. Effective actions in relation to maternal and child health in the border areas need to be prioritized.

Key words Health at the border, Maternal and child health, Maternal and child health care services, Public health, Health care system
Resumo Foz do Iguaçu participa do SIS-Fronteiras e instalou o Centro Materno Infantil (CMI), ofertando atendimento ao pré-natal das gestantes brasileiras moradoras no Paraguai (brasiguaias). Para analisar as características do CMI e comparar o perfil de brasiguaias com gestantes brasileiras residentes no Brasil, conciliou-se abordagem quanti-qualitativa na metodologia. Verificou-se que gestantes brasiguaias atendidas no CMI procuram o local devido à precariedade do sistema de saúde paraguaio. Elas são mais jovens, apresentam maior paridade, menor escolaridade e não têm companheiro, quando comparadas às moradoras no Brasil. Elas omitem onde moram, tentando minimizar a possiblidade de terem atendimento inferior ao das brasileiras do local, ou terem negado seu direito à consulta; e buscam o serviço de obstetrícia tardiamente para evitar a negativa do atendimento. Elas geram custo alto para o município, sobretudo pela desinformação sobre a sua história reprodutiva e gestacional, o que aumenta as chances de serem submetidas a parto cesáreo e de internação da mãe elou do bebê, por complicações. Ações efetivas em relação à saúde materno-infantil nas zonas de fronteira precisam ser priorizadas.

Palavras-chave Saúde na fronteira, Saúde Materno-infantil, Centros de Saúde Materno- Infantil, Saúde Pública, Sistema de Saúde 


\section{Introdução}

As fronteiras do Brasil com os países da América do Sul foram, por décadas, motivo de intervenção pública tendo em vista a necessidade de garantir a segurança nacional ${ }^{1}$. Nos últimos anos, a integração entre as nações tornou-se um dos meios de fortalecimento político e econômico dos países sul-americanos frente à progressiva globalização das economias mundiais ${ }^{2}$. Um exemplo desse processo é a criação do Mercado Comum do Sul (Mercosul), que construiu uma agenda social de integração, regulamentando a livre circulação de pessoas, mercadorias, serviços e capital ${ }^{3}$.

A concepção de fronteira deve levar em consideração a dependência mútua entre os países, pois esses espaços são compartilhados pelos povos transfronteiriços. Assim, a dinâmica populacional e sanitária é complexa nesses territórios, pois são abarcados por uma identidade que transcende os limites estatais. As áreas concebidas pelos limites político-territoriais são constantemente ultrapassadas, e são reforçadas pela criação social promovida pela circulação de produtos e pessoas ${ }^{4}$.

O direito à saúde nas regiões de fronteira é um tema com inserção recente nas esferas governamentais e não governamentais ${ }^{5}$. Em geral, os temas mais relevantes em saúde de fronteira são os que associam saúde às doenças transmissíveis e reemergentes, aos refugiados, ao tráfico e suas consequências. Menos tem se falado do problema do atendimento nos serviços de saúde de cidades de fronteira e de como os habitantes próximos a zona fronteiriça lidam com os sistemas de saúde disponíveis. Por a saúde em zona de fronteira sofrer grande influência pela mobilidade populacional a qual afeta o sistema assistencial, há um incremento no risco de emergência e reemergência de doenças, particularmente entre os grupos mais vulneráveis ${ }^{6}$. Todavia, os distintos desenhos dos sistemas e das políticas de saúde que exibem os países do Mercosul - nos aspectos físicos, financeiros e humanos ou nas abordagens organizacionais da assistência - realçam diversas dificuldades ${ }^{7}$.

Os municípios brasileiros dessas zonas disponibilizam recursos humanos e equipamentos para suas próprias populações ${ }^{1}$, porém também precisam atender uma população flutuante usuária do Sistema Único de Saúde (SUS), não contabilizada em termos de repasses financeiros.Em resposta a esta demanda, o governo federal implantou em 2006 o Sistema Integrado de Saúde das Fronteiras (Sis-Fronteiras), com o intuito de racionalizar a oferta de serviços de saúde para brasileiros que moram no exterior.

Foz do Iguaçu (Paraná), cidade da tríplice fronteira (Brasil, Paraguai e Argentina), participa do Sis-Fronteira. Um dos seus principais desafios está relacionado às gestantes brasiguaias (brasileiras moradoras no Paraguai), que buscavam assistência de saúde no município somente para a realização do parto, visto que este serviço não podia ser negado no hospital brasileiro e a oportunidade de ter atendimento durante a gestação não era oferecida a estas mulheres. O Centro Materno Infantil (CMI), criado com recursos do Sis-Fronteiras, em 2007, objetiva reverter esse quadro, com um atendimento de livre acesso ao pré-natal das gestantes brasiguaias. O CMI é o único serviço no país que atende exclusivamente gestantes brasileiras que moram no exterior.

Embora a busca por serviços de saúde na região de fronteira por brasileiros residentes em outro país seja uma realidade ${ }^{8}$, não foram encontrados estudos que descrevam a dimensão dessa demanda no contexto de consolidação das diretrizes de descentralização e acesso universal e integral do SUS.

Este artigo objetiva analisar as características do serviço de saúde oferecido pelo CMI e descrever o perfil das usuárias gestantes brasileiras moradoras do Paraguai, comparando-as às gestantes residentes em Foz do Iguaçu.

\section{Métodos}

Abordando aspectos qualitativos e quantitativos, o estudo acessou todos os dados de prontuários disponíveis no CMI de Foz do Iguaçu, desde a abertura do serviço (ano de 2006) até dezembro de 2012, período para o qual há informações no banco Sistema de Informações de Nascidos Vivos (SINASC).

Usuárias da assistência do pré-natal do CMI foram definidas como aquelas com pelo menos uma consulta de profissional médico ou enfermeiro. Foram extraídas informações dos prontuários sobre as seguintes variáveis: idade, peso na primeira consulta de pré-natal, altura, cidade de procedência no exterior, número de gestações anteriores, número de partos normais anteriores, número de partos por cesárea anteriores, número de abortos anteriores, idade gestacional na primeira consulta de pré-natal, número de consultas de pré-natal e consulta puerperal. Estas informações foram lançadas em uma tabela no programa Excel, com dupla digitação e posterior 
limpeza de dados. Além disso, foi consultado o banco de dados do SINASC município, para obtenção de dados referentes à gestante (idade, situação conjugal, escolaridade, número de filhos vivos e número de filhos mortos), ao parto (local e tipo de parto) e ao recém-nascido (peso ao nascer e índice de Apgar no primeiro e $5^{\circ}$ minutos).

Esta análise demandou um processo de linkage dos dados do CMI com os bancos do SINASC. As variáveis descritas acima, tanto do banco do CMI quanto do Sistema, constituem as variáveis dependentes das análises estatísticas que se seguem. O processo de linkage foi realizado manualmente, associando-se as duas tabelas a partir do emparelhamento das variáveis relativas às gestantes que eram comuns a ambas as bases: nome, idade, país de residência e ano do parto.

Foram comparados os dados levantados entre os cinco grupos identificados: (A) gestantes brasileiras residentes no Paraguai, que fizeram o pré-natal no CMI e que tiveram o parto em Foz do Iguaçu, declarando-se moradora do Paraguai durante internação no hospital de referência; (B) gestantes brasileiras residentes no Paraguai, que fizeram o pré-natal no CMI e que tiveram o parto em Foz do Iguaçu, porém, declarando-se moradora do Brasil durante internação no hospital de referência; (C) gestantes brasileiras que não fizeram o pré-natal no CMI, mas tiveram o parto em Foz do Iguaçu e se declararam moradoras do Paraguai durante internação no hospital de referência; (D) gestantes brasileiras que não fizeram o pré-natal no CMI, tiveram o parto em Foz do Iguaçu e se declararam moradoras do Brasil durante internação no hospital de referência; e (E) gestantes brasileiras residentes no Paraguai, que fizeram o pré-natal no CMI, porém não fizeram o parto em Foz do Iguaçu. Estes cinco grupos constituem a variável independente das análises estatísticas. Esta análise foi realizada mediante utilização do programa SPSS Statistics (versão 20.0).

As análises quantitativas foram complementadas por entrevistas semiestruturadas com interlocutores-chave brasileiros (gestores municipais e profissionais de saúde do CMI) e do Paraguai (funcionários do Consulado Brasileiro naquele país e representantes da assistência social e em saúde). Estes interlocutores forneceram informações adicionais sobre o sistema pactuado entre as partes, para compreender os problemas relativos às condições de atendimento de saúde das gestantes brasileiras moradoras no exterior.

Um terceiro componente da metodologia incluiu entrevistas semiestruturadas com o ob- jetivo de comparar as características e histórias das gestantes brasileiras que moram no Paraguai e que utilizam (casos) ou não (controles) o serviço de saúde do CMI de Foz do Iguaçu. Esta etapa da pesquisa permitiu explorar as semelhanças e diferenças entre estes dois grupos (com $10 \mathrm{mu}$ lheres em cada), assim como os fatores que influenciaram as decisões sobre o uso ou não do serviço de referência para o acompanhamento de sua gestação. As gestantes controle foram identificadas através de informações fornecidas pelas gestantes caso e através de interlocutores-chave do Paraguai. As análises das entrevistas foram realizadas após leitura e categorização dos temas e dos sentidos dados a eles nos depoimentos das gestantes. Todas as entrevistas foram realizadas nos serviços de saúde - pelo lado brasileiro no CMI e no Paraguai em unidades básicas de saúde de Ciudad del Este e Naranjito.

O estudo foi aprovado pelo Comitê de Ética e Pesquisa da Faculdade de Medicina, da Universidade Federal de Pelotas.

\section{Resultados}

Nesta seção, os resultados quantitativos e qualitativos serão apresentados alternadamente, para cada tópico investigado. Dos cinco grupos de gestantes identificados através das duas bases de dados (Tabela 1), os grupos A, B e E são constituídos por gestantes brasiguaias usuárias do CMI. A Figura 1 mostra a sua procedência, conforme declarada durante a primeira consulta de pré-natal. Em sua maioria, estas são provenientes do Departamento de Alto Paraná (92,1\%), subdivisão administrativa do Paraguai, local mais próximo à fronteira com o Brasil, particularmente das cidades de San Alberto, Hernandarias e Santa Rita, que historicamente receberam mais brasileiros pela migração rural.

O banco de nascimentos do SINASC incluiu dados sobre 34.456 gestantes entre 2006 e 2012 . No total, 33.949 gestantes informaram residir no Brasil (95,7\%) e 1.507 no Paraguai (4,3\%). A partir do processo de linkage entre os bancos de dados do CMI e do SINASC foi possível a classificação das parturientes nos grupos A, B, C e D (Tabela 1).

A Tabela 2 demonstra que as gestantes do grupo B são ligeiramente mais moças $(23,9$ anos), as do grupo E são ligeiramente mais velhas (25,6 anos), diferenças que ficaram no limiar da significância estatística $(P=0,06)$. Não houve diferenças significantes em termos de peso, altura, 
Tabela 1. Distribuição das gestantes por local de residência declarado no hospital de referência de Foz do Iguaçu, por ocasião do parto. Dados do SINASC, 2006-2012.

\begin{tabular}{|c|c|c|c|c|c|}
\hline \multirow{2}{*}{ Pré-natal } & \multicolumn{3}{|c|}{ Parto no hospital de referência } & \multirow[b]{2}{*}{$\begin{array}{l}\text { Usuárias CMI com parto não } \\
\text { registrado no SINASC }\end{array}$} & \multirow{2}{*}{ Total } \\
\hline & $\begin{array}{c}\text { Declarada moradora } \\
\text { do Paraguai }\end{array}$ & $\begin{array}{c}\text { Declarada } \\
\text { moradora do Brasil }\end{array}$ & Total & & \\
\hline CMI & $A=313$ & $\mathrm{~B}=131$ & 444 & $\mathrm{E}=231$ & 675 \\
\hline Não CMI & $C=1.194$ & $\mathrm{D}=33.818$ & 34.012 & & \\
\hline Total & 1.507 & 33.949 & 34.456 & & \\
\hline
\end{tabular}

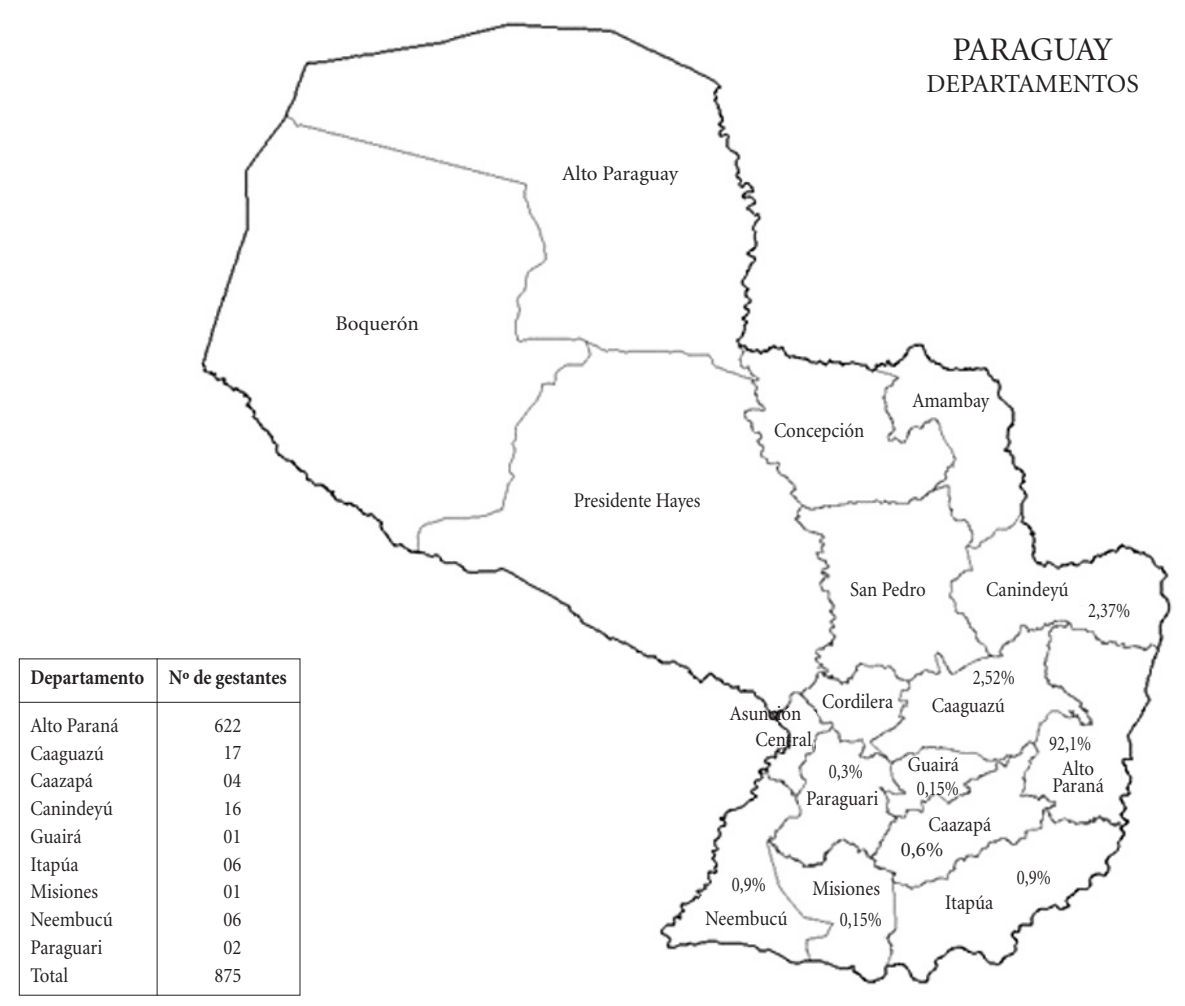

Figura 1. Locais de procedência declarados pelas gestantes do Centro Materno Infantil (CMI) na primeira consulta de pré-natal. Dados CMI, 2006-12.

Tabela 2. Média das variáveis dependentes quantitativas conforme os grupos de gestantes. Dados do CMI, 2006-2012.

\begin{tabular}{lrrrrrrrr}
\hline Grupo & $\begin{array}{r}\text { Idade } \\
(\text { anos })\end{array}$ & $\begin{array}{r}\text { Peso } \\
(\mathbf{k g})\end{array}$ & $\begin{array}{c}\text { Altura } \\
(\mathbf{m})\end{array}$ & Gestações $^{*}$ & $\begin{array}{r}\text { Partos } \\
\text { prévios }\end{array}$ & $\begin{array}{r}\text { Cesáreas } \\
\text { prévias }\end{array}$ & $\begin{array}{r}\text { Abortos } \\
\text { prévios }\end{array}$ & $\begin{array}{c}\% \\
\text { cesáreas }^{* *}\end{array}$ \\
\hline $\mathrm{A}$ & 24,9 & 64,2 & 1,59 & 2,60 & 1,12 & 0,31 & 0,16 & 26 \\
$\mathrm{~B}$ & 23,9 & 66,4 & 1,60 & 2,27 & 0,90 & 0,23 & 0,14 & 28 \\
$\mathrm{E}$ & 25,6 & 65,0 & 1,58 & 2,48 & 0,99 & 0,30 & 0,24 & 30 \\
Total & 24,9 & 64,9 & 1,59 & 2,50 & 1,03 & 0,29 & 0,18 & 27 \\
Valor P & 0,06 & 0,23 & 0,10 & 0,23 & 0,39 & 0,52 & 0,14 & 0,65 \\
\hline
\end{tabular}

"Incluindo a gestação no momento da consulta de pré-natal. "* Proporção de cesáreas relativamente ao número total de partos prévios. 
paridade, número de partos vaginais, partos cesáreos e abortos prévios.

Além de estudar a paridade média, foi possível investigar o percentual de primigestas em cada grupo, de acordo com o SINASC. Este percentual foi mais elevado no grupo B (45\%) do que no A (38\%) ou E (33\%) $(\mathrm{P}=0,058)$. Para as 395 mães que não eram primigestas, calculou-se também o percentual de cesáreas em partos prévios, mas não houve diferença significativa entre os três grupos. Os percentuais de mães com seis ou mais consultas, conforme preconizado pelo Ministério da Saúde (MS), foram 42\%, 31\% e $25 \%$, respectivamente $(\mathrm{P}<0,001)$.

Nos dados do SINASC avaliou-se a procura da mulher pelo serviço no primeiro trimestre de gestação - indicador da boa qualidade do serviço em termos de diagnóstico e acompanhamento precoce. Foram observados os seguintes percentuais de procura: grupo A 50\%, grupo B 37\% e grupo $\mathrm{E} 46 \%(\mathrm{P}=0,052)$. A procura da puérpera pela consulta pós-natal, que deve ocorrer em até um mês após o parto, apresentou os percentuais de $60 \%$ no grupo A, $50 \%$ no grupo B e $25 \%$ no grupo $\mathrm{E}(\mathrm{P}<0,001)$.

Para investigar tendências temporais nos dados do CMI (Tabela 3), foram combinados para fins de análise os anos de 2006 e 2007, assim como os de 2011 e 2012. O número pequeno de gestantes $(\mathrm{N}=39)$ em 2006 decorreu do pouco tempo de atendimento naquele ano, que foi o primeiro do serviço. No ano de 2012, a análise foi restrita a mulheres cujo parto ocorreu até 31 de dezembro desse ano e que, portanto, poderiam ser encontradas no SINASC. Não houve nenhuma tendência clara de mudanças no tamanho dos grupos ao longo do tempo $(\mathrm{P}=0,28)$, e o número médio de consultas não variou significativamen- te no mesmo período $(\mathrm{P}=0,55)$. As variáveis que apresentaram tendências temporais significativas foram altura (aumento), número de gestações prévias e de partos vaginais (redução), abortos (aumento) e percentual de cesáreas (aumento).

Voltando à Tabela 1, observa-se que a maioria das mulheres que declararam no momento do parto residirem no Paraguai não consultou no CMI. Estimou-se a cobertura deste serviço em 21\% (grupo A dividido pela soma dos grupos A e C). Não foram incluídas no cálculo de cobertura as mulheres do grupo B, pois mesmo tendo seu pré-natal realizado no $\mathrm{CMI}$, elas se declararam como moradoras do Brasil no momento do parto, podendo de fato não residirem no Paraguai, mas empregarem tal argumento para usufruir do serviço ambulatorial. Da mesma forma, as mulheres do grupo $\mathrm{D}$, que se declaram moradoras do Brasil quando chegam para o parto no hospital de referência e não utilizam os serviços do CMI. Estas últimas também podem residir no Paraguai e informarem que residem no Brasil para evitar possíveis dificuldades no atendimento à saúde.

Este achado foi investigado com os profissionais e mães entrevistados. Estes relataram que, mesmo após a implantação do CMI, tanto brasileiros quanto paraguaios desconheciam os serviços oferecidos no Centro. Essa desinformação se reflete nos comportamentos apresentados pelas brasiguaias, que continuam a procurar diretamente o hospital em busca de atendimento para o parto. Não surpreendentemente, o consenso nos depoimentos ressaltou negativamente a quantidade de registros burocráticos necessários para a incorporação dessas mulheres ao SUS. A maioria dos entrevistados reafirmou a necessidade imediata de a política de saúde na região da fronteira se concretizar no cotidiano dos serviços

Tabela 3. Características das gestantes conforme o ano da primeira consulta de pré-natal. Dados do CMI, 2006-12.

\begin{tabular}{lrrrcccr}
\hline \multicolumn{1}{c}{ Ano } & $\begin{array}{r}\text { Idade } \\
(\mathbf{a n o s})\end{array}$ & $\begin{array}{r}\text { Peso } \\
(\mathbf{k g})\end{array}$ & $\begin{array}{c}\text { Altura } \\
(\mathbf{m})\end{array}$ & Gestações $^{*}$ & $\begin{array}{c}\text { Partos } \\
\text { prévios }\end{array}$ & $\begin{array}{r}\text { Abortos } \\
\text { prévios }\end{array}$ & $\begin{array}{c}\text { Cesáreas } \\
\text { prévias }(\%)\end{array}$ \\
\hline $2006-7$ & 24,7 & 64,8 & 1,57 & 1,57 & 1,21 & 0,11 & 23 \\
2008 & 26,2 & 63,4 & 1,58 & 1,58 & 1,38 & 0,17 & 23 \\
2009 & 24,7 & 63,4 & 1,59 & 1,59 & 0,97 & 0,13 & 24 \\
2010 & 24,8 & 65,2 & 1,60 & 1,60 & 0,99 & 0,19 & 29 \\
$2011-12$ & 24,6 & 66,3 & 1,60 & 1,60 & 0,80 & 0,24 & 34 \\
Total & 24,9 & 64,9 & 1,59 & 1,59 & 1,03 & 0,18 & 27 \\
$\mathrm{P}^{* *}$ & 0,292 & 0,091 & 0,000 & 0,000 & 0,004 & 0,033 & 0,045 \\
\hline
\end{tabular}

*Incluindo a gestação no momento da consulta de pré-natal. "* Teste para tendência. 
menos burocratizados. Suas preocupações maiores envolvem questões práticas, principalmente $o$ aporte financeiro, que é escasso para desenvolver e atender as necessidades da área. Os acordos e tratados bilaterais e trilaterais, como é o caso de Foz do Iguaçu, ainda demandam contatos ministeriais para concretizar, por exemplo, a formalização do atendimento das necessidades básicas em saúde, como a confecção ou a portabilidade do cartão-SUS. Apesar de o Sis-Fronteiras haver garantido, desde 2006, pelo MS, o repasse financeiro de recursos específicos para a implantação de estruturas para o atendimento de brasiguaios, os recursos são finitos e inferiores ao custo real dessas ações, conforme os depoimentos dos profissionais. Portanto, o atendimento a essas mulheres tem impacto negativo na rotina, nos indicadores do serviço e no desenvolvimento das atividades de saúde local. Após a implementação do Mercosul, o acesso aos serviços de saúde em Foz do Iguaçu - embora tenha sido facilitado para brasileiros moradores do exterior e seus descendentes - fez com que este contingente populacional se tornasse invisível nos cálculos do repasse financeiro do governo. Os brasileiros vindos do Paraguai, portanto, referem um acolhimento discriminatório presente na estrutura implantada nos serviços de saúde de Foz do Iguaçu.

A distribuição das gestantes nos serviços, tal como ela ocorre, e suas características, analisadas enquanto grupos, estão apontadas na Tabela 4. Resumidamente, os grupos A e D são parecidos, porém o $\mathrm{A}$ apresenta maior paridade. $\mathrm{O}$ grupo B é o mais jovem, como apontado pelos dados do CMI, e o grupo C é o mais velho, cujos filhos têm mais baixo peso ao nascer. Essas diferenças, com exceção da variável Apgar $5^{\circ}$ minuto, foram estatisticamente significativas. Os grupos A e B incluem $23 \%$ e $23,7 \%$ respectivamente, de gestantes adolescentes, enquanto os grupos C e D apenas $13,3 \%$ e $19,4 \%$. O grupo A ainda possui a menor proporção de primíparas $(38,5 \%)$ e a maior de multíparas (12,9\%). Quanto ao estado civil da usuária, nos grupos A e B concentram-se as gestantes solteiras, com percentual de $72,3 \%$ e $75,2 \%$ respectivamente, e nos grupos $\mathrm{C}$ e $\mathrm{D}$, concentram-se as casadas, com $38,3 \%$ e $30 \%$ cada. Vale salientar o alto percentual de mulheres que não se declaram casadas, possivelmente devido às dificuldades burocráticas de oficializar as uniões para brasileiras residentes no Paraguai. Quanto à escolaridade, o grupo A possui a menor formação escolar, com percentual de $22,8 \%$ de usuárias com menos de quatro anos de estudo, enquanto o grupo C tem $33,8 \%$ de usuárias com 12 ou mais anos de escolaridade. Quanto ao tipo de parto, o grupo $\mathrm{C}$ apresenta o maior percentual de cesáreas $(63,9 \%)$ e também o maior percentual de crianças com baixo peso ao nascer $(11,1 \%)$. Os grupos A e B apresentam as menores prevalências de baixo peso ao nascer. O dado de $1,5 \%$ de baixo peso no grupo B precisa ser interpretado com cautela devido ao pequeno número de gestantes (131 mulheres) incluídas nesse grupo, mas assim mesmo seu intervalo de confiança de $95 \%$ variou de 0 a 3,7\%. Portanto, não há evidências de que a gestante que vem do Paraguai afeta negativamente os índices de qualidade do pré-natal, parto e puerpério brasileiros, bem como as taxas de mortalidade materno-infantil.

Muito da preocupação citada pelos profissionais em saúde de Foz do Iguaçu está relacionada aos indicadores de saúde locais. $\mathrm{O}$ atendimento das brasiguaias parece também estar relacionado à repercussão nesses indicadores, como já citado. $O$ fato da preocupação se concentrar mais no bebê do que na forma de tratamento da mãe gestante é um bom exemplo. Em nenhum momento os profissionais de saúde falaram da importância de acompanhar esse bebê durante vários anos

Tabela 4. Média das variáveis dependentes quantitativas conforme os grupos de gestantes. Dados do SINASC, 2006-2012.

\begin{tabular}{lcccccc}
\hline Grupo & $\begin{array}{c}\text { Idade da mãe } \\
\text { (anos) }\end{array}$ & $\begin{array}{r}\text { Número de } \\
\text { filhos vivos }\end{array}$ & $\begin{array}{c}\text { Número de } \\
\text { filhos mortos }\end{array}$ & $\begin{array}{r}\text { Apgar 1o } \\
\text { minuto }\end{array}$ & $\begin{array}{r}\text { Apgar 5o } \\
\text { minuto }\end{array}$ & $\begin{array}{c}\text { Peso ao nascer } \\
\text { (g) }\end{array}$ \\
\hline A & 25,2 & 1,41 & 0,11 & 8,6 & 9,6 & 3.262 \\
B & 24,2 & 1,12 & 0,08 & 8,5 & 9,6 & 3.388 \\
C & 26,8 & 1,02 & 0,11 & 8,5 & 9,7 & 3.139 \\
D & 25,8 & 1,04 & 0,08 & 8,6 & 9,7 & 3.196 \\
Total & 25,8 & 1,04 & 0,08 & 8,6 & 9,7 & 3.195 \\
Valor P & $<0,001$ & $<0,001$ & 0,03 & 0,04 & 0,26 & $<0,001$ \\
\hline
\end{tabular}

* Incluindo a gestação no momento da consulta de pré-natal. ${ }^{* *}$ Teste para tendência. 
para prevenir problemas posteriores que possam afetar sua saúde, tampouco em fazer com que essas mulheres retornem ao serviço para prevenção de doenças.

O CMI de Foz do Iguaçu deveria ser a porta de entrada preferencial do SUS para as gestantes brasileiras residentes no exterior, independente do local de moradia e do motivo que a levou para viver em outro país. Todavia, isso não ocorre para todas. As gestantes oriundas do Paraguai que o utilizam (gestantes-caso) referem que buscam o serviço em virtude da precariedade de recursos físicos e materiais do serviço paraguaio, com depoimentos que enfatizam a descredibilidade dos profissionais de saúde e os altos preços cobrados para qualquer tipo de tratamento ou consulta no país vizinho ("eu não confio [neles]", como apontaram várias gestantes).

A distância e o custo de transporte devem ser computados aos gastos mensais das gestantes brasileiras moradoras do Paraguai. Algumas distâncias ultrapassam inclusive a faixa de fronteira e exigem que a gestante precise levantar muito cedo para chegar ao serviço que abre às 08:00 horas, de segunda a sexta-feira. O transporte mais comum é o carro familiar, mas ônibus intermunicipal e táxi também fazem parte das opções dessas mulheres que, em alguns municípios, contam com o serviço particular de uma van para trazê-las. O motorista desse serviço foi um dos interlocutores-chave do presente estudo. Este brasileiro, que conhece a rede assistencial de saúde de Foz do Iguaçu, atua também como guia e orientador do sistema quanto à procura não só de gestantes, mas de outros brasiguaios que buscam atendimento nos serviços de saúde da cidade.

O Quadro 1 resume os principais achados dos cinco grupos de gestantes. A classificação adotada a priori, sem conhecer as características médicas, demográficas e sociais das gestantes, mostrou-se eficiente ao discriminar cinco grupos com características razoavelmente distintas. As gestantes dos grupos A e B (brasiguaias) são as mais semelhantes entre si e possuem um padrão de pré-natal mais próximo ao preconizado pelo MS do Brasil - realizam seis ou mais consultas de pré-natal com mais frequência e retornam para a consulta puerperal, também procuram mais precocemente o serviço em comparação as gestantes do grupo C, que também são moradoras do Paraguai, não realizaram o pré-natal no CMI, mas que fizeram o parto em Foz do Iguaçu. Comparando os dados dos grupos A e B com o grupo de referência (D), os dois primeiros possuem fatores de risco gestacionais elevados no que se refere à idade, escolaridade, ao percentual de adolescentes gestantes, ao estado civil (casadas) e número de filhos (multíparas). Porém, essas gestantes apresentam desfechos melhores ou iguais aos desse grupo de referência para Apgar, peso ao nascer e taxas de cesáreas. Tais dados fornecem alguma evidência sobre a qualidade do serviço do CMI frente ao pré-natal realizado no município de Foz do Iguaçu. Todavia, cabe questionar se a qualidade do atendimento prestado ao grupo D pode ser qualificado como de referência para os serviços.

A maioria das gestantes-caso (Grupos A, B e E na Tabela 4) conhecia o serviço prestado pelo CMI em virtude de já havê-lo usado em outra gestação, ou através de indicação de alguma conhecida. Isso também ocorreu quando elas apresentavam vínculo com pessoas de Foz do Iguaçu, que as incentivam buscar o serviço na cidade, provavelmente em decorrência da condição vulnerável que a gestante se encontra e a consideração que desperta na sociedade. Não é incomum o acompanhamento dessas pessoas, inclusive na busca pelo serviço e na oferta de abrigo para as gestantes. Aquelas que não dispõem de condições financeiras para o deslocamento são as que chegam ao serviço tardiamente, com a intenção de permanecer no Brasil até a hora do parto, hospedando-se com algum parente ou conhecido. Essas relatam que buscariam o serviço mais cedo se soubessem de seus direitos e tivessem condições financeiras favoráveis para o acompanhamento mensal.

A qualidade do serviço prestado no CMI e nas demais unidades de saúde de Foz do Iguaçu, também é considerado pelas gestantes-caso. Seus relatos indicam que possuem certos privilégios adquiridos pela condição de gestantes, tais como: atendimento preferencial; consideração com os atrasos; agendamento de exames laboratoriais e de imagem priorizados. Em algumas situações, os familiares das brasiguaias alugam um local em Foz do Iguaçu para que elas possam ter garantido o acesso ao sistema e ao parto gratuito. Cabe ressaltar que nenhuma das gestantes relatou receio ou medo ao se declarar moradora do Paraguai no CMI. O mesmo não ocorreu em outros serviços que atendem gestantes-caso. Mesmo sabendo do direito do cidadão à saúde, muitas preferem usar o endereço do parente ou conhecido residente no Brasil, que ofereceu abrigo nesse período. Há relato de que um dos locais de referência solicitou um comprovante de endereço do Brasil para agilizar o processo de internação. 
Quadro 1. Resumo dos principais resultados nos cinco grupos de gestantes.

\begin{tabular}{|c|c|c|c|c|c|c|}
\hline Grupo & $\begin{array}{c}\text { Local de } \\
\text { residência }\end{array}$ & Pré-natal & $\begin{array}{c}\text { Local declarado } \\
\text { no parto }\end{array}$ & Parto & Características & Interpretação \\
\hline A & Paraguai & CMI & Paraguai & Foz do Iguaçu & $\begin{array}{l}\text { Em relação ao grupo D, } \\
\text { inclui mais adolescentes, } \\
\text { mais multíparas, mais } \\
\text { solteiras, escolaridade } \\
\text { marcadamente menor, } \\
\text { além de percentual de } \\
\text { cesáreas e baixo peso ao } \\
\text { nascer menores. }\end{array}$ & $\begin{array}{l}\text { Estas mulheres reapresentam } \\
\text { a clientela do CMI, mulheres } \\
\text { pobres, com mais filhos, que } \\
\text { residem no Paraguai, mas usam } \\
\text { intensamente os serviços de } \\
\text { saúde do Brasil. }\end{array}$ \\
\hline B & Paraguai & CMI & Brasil & Foz do Iguaçu & $\begin{array}{l}\text { Mulheres muito } \\
\text { parecidas com o grupo A, } \\
\text { mas que consultaram um } \\
\text { pouco menos no CMI. }\end{array}$ & $\begin{array}{l}\text { Não há diferenças claras entre } \\
\text { este grupo e o anterior, a não } \\
\text { ser que a maior utilização do } \\
\text { CMI pelo grupo A deixe aquelas } \\
\text { mulheres conscientes de que } \\
\text { não há problema em declarar } \\
\text { no momento do parto que são } \\
\text { residentes no exterior. }\end{array}$ \\
\hline $\mathrm{C}$ & Paraguai & Ignorado & Paraguai & Foz do Iguaçu & $\begin{array}{l}\text { Mulheres de alta } \\
\text { escolaridade, casadas, } \\
\text { mais velhas, menor } \\
\text { paridade, altas taxas de } \\
\text { cesáreas, alto índice de } \\
\text { baixo peso ao nascer. }\end{array}$ & $\begin{array}{l}\text { Mulheres de mais alto nível } \\
\text { socioeconômico, residem no } \\
\text { Paraguai, mas não usam o } \\
\text { CMI, possivelmente fazem } \\
\text { pré-natal particular mas } \\
\text { vêm ao Brasil para ter seu } \\
\text { filho, preferencialmente por } \\
\text { cesariana. }\end{array}$ \\
\hline $\mathrm{D}$ & Brasil & Outro & Brasil & Foz do Iguaçu & $\begin{array}{l}\text { Mulheres brasileiras } \\
\text { residentes no Brasil. }\end{array}$ & Grupo de referência. \\
\hline $\mathrm{E}$ & Paraguai & CMI & Ignorado & Outro & $\begin{array}{l}\text { Mulheres similares aos } \\
\text { grupos A e B em termos } \\
\text { de variáveis coletadas } \\
\text { durante o pré-natal, } \\
\text { mas que fazem menos } \\
\text { consultas, iniciam o pré- } \\
\text { natal mais tarde, e voltam } \\
\text { menos para a consulta } \\
\text { puerperal. }\end{array}$ & $\begin{array}{l}\text { Mulheres completamente } \\
\text { radicadas no Paraguai, } \\
\text { comparecem ao CMI poucas } \\
\text { vezes, possivelmente apenas } \\
\text { para realizar exames, e têm } \\
\text { seu parto posteriormente no } \\
\text { Paraguai. }\end{array}$ \\
\hline
\end{tabular}

As gestantes-controle apontam positivamente a gratuidade no atendimento das consultas de pré-natal nos postos de saúde do Paraguai, mas que alguns desses serviços destratam as gestantes brasileiras pelo mesmo sentimento apresentado pelos profissionais no Brasil, ou seja, uso indevido do sistema por esta população. Estas gestantes precisam ainda pagar por exames laboratoriais, de imagem e alguns medicamentos não disponíveis pelo sistema daquele país. Partos vaginais podem ser realizados nos postos de saúde desde que a gestante já esteja em trabalho de parto, pois os hospitais de referência estão concentrados nas cidades maiores. Partos vaginais e internações da gestante e do recém-nascido nos hospitais de referência para estes postos são gratuitos, sendo cobrados somente os materiais e medicamentos utilizados no procedimento. No entanto, o parto cesáreo tem de ser custeado pelas gestantes; segundo elas, ele é caro, mas "de qualidade" (sic). 
Das 10 gestantes-controle, apenas uma relatou conhecer o serviço prestado pelo CMI. Esta mencionou haver feito o pré-natal da gestação anterior no Brasil, mas não pôde fazê-lo na atual gestação pelo custo de transporte mensal. Além disso, relatou insatisfação em ter que permanecer novamente na casa de parentes. A situação financeira para o custeio dessa viagem para o pré-natal no Brasil foi recorrente nos depoimentos das gestantes-controle. $\mathrm{O}$ dinheiro gasto com o transporte seria superior aos custos hospitalares do parto no Paraguai. O que pode ser notado pela proporção de gestantes que procuram o CMI conforme localidade de moradia no Paraguai (Figura 1). Além disso, relatam confiarem no serviço ambulatorial prestado pelo posto de saúde paraguaio e, principalmente, no profissional que realiza o pré-natal.

Novamente a questão dos documentos é mencionada como um entrave. A ausência de documentos brasileiros e do cartão-SUS encarece a busca pelo serviço no Brasil. Grande parte das gestantes-controle não possui registro brasileiro, cuja confecção é paga. Por residirem no Paraguai, o contrário é verdadeiro, elas preferem ter documentos paraguaios - ao invés de brasileiros - para evitar problemas relacionados à residência no $\mathrm{Pa}$ raguai. Nenhuma das gestantes-controle demonstrou interesse imediato de fazer o parto no Brasil.

\section{Discussão}

Ao avaliar dados dos serviços prestados pelo CMI e as percepções dos profissionais de saúde do Brasil e do Paraguai e das gestantes dos grupos caso e controle, os principais achados deste estudo demonstram que:

(1) Os profissionais identificam grupos distintos de gestantes nos serviços de saúde, que se diferem nas condições que podem administrar seu pré-natal, parto e puerpério e realizá-los ou não no Brasil;

(2) As gestantes que utilizam o serviço do CMI, com um número maior de consultas de acompanhamento de pré-natal e puerpério, possuem residência fixa em locais próximos à Foz do Iguaçu. Elas são ainda mais jovens, sem companheiro, com menor escolaridade e maior paridade, e menor renda (conforme verificou o estudo qualitativo), se comparadas às gestantes do grupo de referência, ou seja, brasileiras moradoras de Foz do Iguaçu. Relatam buscar o serviço no Brasil pela precariedade do sistema no lado paraguaio e custo do atendimento;
(3) As gestantes que menos utilizaram o CMI ou cuja utilização foi nula relataram razões idênticas às descritas pelo grupo anterior (custo e atendimento não disponível). Todavia, essas mulheres são mais velhas, casadas, possuem maior escolaridade e menor paridade se comparadas às que utilizam o CMI.

Para tentar driblar a sua situação e as consequências da mesma sobre a forma com que são tratadas pelos serviços, as gestantes brasiguaias e seus familiares criam estratégias para receberem atendimento no Brasil. As estratégias mais comumente usadas pelas gestantes brasiguaias (e familiares) incluem: (1) a omissão daqueles que moram no Paraguai, pois podem receber um atendimento inferior ao recebido pelas brasileiras ou terem negado o seu direito - ficando assim, duplamente desassistidas; e (2) buscar o serviço de obstetrícia tardiamente, para evitar a negativa do atendimento. O custo desse comportamento é visto como sendo alto para o sistema público de Foz do Iguaçu, sobretudo porque há desinformação quanto à história reprodutiva e gestacional, aumentando as chances de serem submetidas a parto cesáreo e de internação da mãe e/ou do bebê por complicações advindas de uma gestação desacompanhada. O Centro específico para atender essas mulheres pouco atua diante da demanda existente naquela fronteira. Vale ainda notar que o CMI foi criado para evitar que as gestantes utilizem diretamente o serviço de atenção ao parto no Brasil, sem realizar um pré-natal de qualidade. Os resultados acima mostram que esta intenção teve um sucesso apenas parcial. O sistema fragmentado de atenção à saúde torna-se, muitas vezes, um modelo incapaz de prestar uma assistência continuada à população9 ${ }^{9}$ No Brasil, o local de residência, por exemplo, influencia fortemente o acesso aos serviços de saúde, bem como, a classificação positiva do atendimento pelo usuário - aumentando a chance de o morador procurar ou não a unidade de saúde mais próxima ${ }^{10}$.

Chama a atenção que a percepção dos gestores brasileiros, de que as brasiguaias estariam contribuindo para piorar os indicadores de saúde de Foz do Iguaçu, não encontra respaldo nos dados epidemiológicos oriundos da análise do SINASC. A única possível ressalva é o grupo C, composto de gestantes de alto nível socioeconômico que se dirigem ao Brasil para fazer partos cesáreos e, possivelmente como consequência de cesáreas eletivas, apresentam maiores índices de baixo peso ao nascer em seus filhos.

Observou-se que a clientela do CMI tem mudado positivamente ao longo do tempo, conforme 
alguns indicadores analisados. As variáveis que apresentaram tendências temporais significativas foram: aumento da estatura média das gestantes e redução do número de gestações prévias. Todavia, essa clientela apresentou um declínio no número de partos vaginais e um aumento no número de abortos e do percentual de partos cesáreos. Essas mudanças são compatíveis com as características evolutivas apresentadas pelas mães do Brasil ${ }^{11}$.

Amplas transformações sociais e tecnológicas afetaram os indicadores de saúde materno-infantis no Brasil, incluindo a urbanização e mudanças na escolaridade e na inserção social das mulheres, aliadas à organização da Atenção Básica com a ampliação da cobertura das intervenções de saúde dirigidas às gestantes ${ }^{11}$. A taxa total de fecundidade reduziu drasticamente nas últimas três décadas, porém essa redução foi mais lenta entre as mães adolescentes. $\mathrm{O}$ acesso ao serviço de pré-natal e ao parto institucionalizado também aumentou, porém este processo foi acompanhado por medicalização excessiva, sendo que os partos cesáreos atualmente correspondem a quase 50\% dos nascimentos no Brasil'. Outra constatação negativa é a frequência de abortos ilegais, sendo que uma gestação a cada quatro foi interrompida ${ }^{11}$.
Este estudo destacou a necessidade de que os serviços e a população entendam os direitos das gestantes assim como os deveres dos profissionais da saúde. Além disso, se impõe que os locais de referência materno-infantil sejam de fato integrados ao Sis-Fronteiras e em tempo adequado para o atendimento a contento do programa de pré-natal. A integração em forma de rede bem estruturada e informada para o adequado fluxo dessas mulheres e entre os locais com distintas complexidades de atendimento precisa ser construída e devidamente comunicada à população -alvo. Além disso, é fundamental que se estabeleça uma relação eficaz entre os serviços de saúde e os serviços assistenciais. A integração entre os países da fronteira é condição essencial para acelerar os processos de desenvolvimento econômico e social para essas regiões ${ }^{12}$. Destaca-se ainda que muitos dos problemas ligados ao atendimento materno-infantil na fronteira estão atrelados à história, na qual os brasiguaios ainda estão em busca de um apoio, neste caso, para fazer valer os seus diretos em saúde. É uma população que está literalmente na fronteira, entre seus direitos, identidade e visibilidade.

\section{Colaboradores}

F Mello, CG Victora e H Gonçalves participaram da concepção e delineamento do estudo e participaram das análises e redação e revisão crítica do artigo. F Mello foi responsável pela condução do trabalho de campo. 


\section{Referências}

1. Gadelha CAG, Costa L. Integração de fronteiras: a saúde no contexto de uma política nacional de desenvolvimento. Brasil. Cad Saude Publica 2007; 23(Supl. 2):S214-S226.

2. Cassiolato JE, Lastres MM. Globalização \& inovação localizada. Brasília: Instituto Brasileiro de Informação em Ciência e Tecnologia, Ministério da Ciência e Tecnologia; 1999.

3. Giovanella L, Guimarães L, Nogueira VMR, Lobato LVC, Damacena GN. Saúde nas fronteiras: acesso e demandas de estrangeiros e brasileiros não residentes ao SUS nas cidades de fronteira com países do Mercosul na perspectiva dos secretários municipais de saúde. Cad Saude Publica 2007; 23(Supl. 2):S251-S266.

4. Albuquerque JLC. A dinâmica das fronteiras: os brasiguaios na fronteira entre o Brasil e o Paraguai. São Paulo: Annablume; 2010.

5. Augustini J, Nogueira VMR. A descentralização da política nacional de saúde nos sistemas municipais na linha da fronteira Mercosul. Serv. Social e Sociedade 2010; (102):222-243.

6. Levino A, Carvalho EF. Análise comparativa dos sistemas de saúde da tríplice fronteira: Brasil/Colômbia/Peru. Rev. Panamericana Salud Publica 2011; 30(5):490-500.

7. Draibe SM. Coesão social e integração regional: a agenda social do Mercosul e os grandes desafios das políticas sociais integradas. Brasil. Cad Saude Publica 2007; 23(Supl. 2):S174-S183.
8. Fundo das Nações Unidas para Infância (Unicef). Situação das crianças e adolescentes na Tríplice fronteira entre Argentina/Brasil/Paraguai: desafios e recomendações. Curitiba: Itaipu Binacional; 2005.

9. Mendes EV. As redes de atenção à saúde. Cien Saude Colet 2010; 15(05):2297-2305.

10. Bonello AALM, Corrêa CRS. Acesso aos serviços básicos de saúde e fatores associados: estudo de base populacional. Cien Saude Colet 2014; 19(11):4397-4406.

11. Victora CG, Aquino EML, Leal MC, Monteiro CA, Barros FC, Szwarcwald CL. Saúde de mães e crianças no Brasil: progressos e desafios. The Lancet 2011; 32:46.

12. Machado MH, Paula AE, Aguiar Filho W. O trabalho em saúde no Mercosul: uma abordagem brasileira sobre a questão. Brasil. Cad Saude Publica 2007; 23(Supl. 2):S292-S301.

Artigo apresentado em 09/07/2014

Aprovado em 02/03/2015

Versão final apresentada em 04/03/2015 